\title{
Restraint in mental health settings: is it time to declare a position?
}

\author{
Faisil Sethi, John Parkes, Eric Baskind, Brodie Paterson and Aileen O’Brien
}

\section{Summary}

The emergence of a drive to reduce restrictive interventions has been accompanied particularly in the UK by a debate focussing on restraint positions. Any restraint intervention delivered poorly can potentially lead to serious negative outcomes. More research is required to reliably state the risk attached to a particular position in a particular clinical circumstance.

\section{Declaration of interest}

F.S. is a consultant psychiatrist in Psychiatric Intensive Care at the Maudsley Hospital, London. He is on the Executive Committee of the National Association of Psychiatric Intensive Care and Low Secure Units, and was a member of the National Institute for Health and Care Excellence Guideline Development Group for the Short-Term Management of Aggression and Violence (2015). J.P. is a senior lecturer at the Faculty of Health and Life Sciences, Coventry University. E.B. is a consultant and expert witness in violence reduction and the use of physical interventions, independent expert to the High Secure Hospitals Violence Reduction Manual Steering Group and a member of the College of Policing Guideline Committee Steering Group and Mental Health Restraint Expert Reference Group. B.P. is the clinical director for Crisis and Aggression Limitation and Management (CALM) Training and formerly a senior lecturer for the Faculty of Health, University of Stirling. He is a nurse and psychotherapist and presently chairs the European Network for Training in the Management of Aggression. A.O'B. is a consultant psychiatrist, the Director of Educational Programmes for the National Association of Psychiatric Intensive Care and Low Secure Units, and the Dean for Students at St George's University of London.

\section{Copyright and usage}

(c) The Royal College of Psychiatrists 2018.
There is a broad international consensus that where any form of coercion is used, preference should be given to the least restrictive and least dangerous measure. ${ }^{1}$ Physical restraint is sometimes used as a discrete intervention, separate to the use of other coercive interventions such as mechanical restraint, enforced medication and seclusion, but where such options are available restraint will almost invariably be used to facilitate their application. Coercive interventions exist in a dynamic clinical context, where the availability of one intervention may have an impact on the frequency and nature of another.

The use of coercive interventions has historically been driven by an interaction between local and national cultures rather than being evidence based, and a number of countries are working towards reducing such interventions. ${ }^{2}$ In the UK, this practice is comparatively unusual in that mechanical restraint ${ }^{3}$ and seclusion are used infrequently; this is arguably a legacy of the restraint reduction movement of the 1800 s which has also been an emergent policy theme tied to high profile fatalities in the UK. The focus on decreasing the number of restraints has been accompanied by a focus on reducing specific types of physical restraint, especially those in which the patient is held in the prone position; similar concerns have been expressed in Australia and New Zealand. ${ }^{4}$

In 2013, the UK charity Mind published a report calling for an end to the 'life-threatening' practice of face-down restraint. ${ }^{5}$ According to Mind's analysis, at least 3439 patients were restrained in a face-down position in 2011-2012. This report was published in the context of wider public concerns after highly publicised deaths of patients post-restraint, in police custody and mental health settings, and the scandal of the abuse of people with intellectual disabilities (also known as learning disabilities in UK health services) at Winterbourne View. ${ }^{6}$ The authors suggested that restrictive interventions were being used for too long, not as a last resort, and sometimes to 'inflict pain, humiliate or punish'.

In 2014, the 'Positive and Safe' programme launched by the UK Department of Health sought to transform policy, practice, reporting and accountability around the use of restrictive interventions in mental health and intellectual disability services. ${ }^{7}$ This was closely followed by the 2015 National Institute for Health and Care Excellence (NICE) guidelines which suggested an avoidance of taking a patient to the floor and a preference for supine over prone restraint. The guidance also suggested considering the use of seclusion or rapid tranquilisation if the restraint lasts for more than 10 minutes. $^{8}$

The revised Code of Practice of the UK Mental Health Act 1983 (MHA) states that unless there are cogent reasons for doing so, there must be no planned restraint of a person whereby they are forcibly laid on their front. ${ }^{9}$ The Care Quality Commission produced a guide in 2015 focusing on the importance of training, individual care plans and debriefing. ${ }^{10}$ Concerns about physical risk during restraint have also led to patient safety alerts for both England and Wales stressing the importance of monitoring vital signs. ${ }^{11,12}$

The National Health Service Benchmarking Network (NHSBN) has collected recent data on the use of restraint in England. Figure 1 summarises the totals/rates for (prone) restraint in over $90 \%$ of the beds in England in January 2016. The figure summarises the results from the NHSBN Restraint Audit (2016) ${ }^{13}$ and displays a striking variation in practice in different clinical specialities across the security spectrum.

A prerequisite to the NHSBN's work was definitional clarity over what constituted (prone) restraint. This led to definitions for restrictive interventions, defined as 'planned or reactive acts on the part of other person(s) that restrict an individual's movement, liberty and/or freedom to act independently in order to take immediate control of a dangerous situation where there is a real possibility of harm to the person or others'. Restraint was defined as 'any restrictive intervention involving direct physical contact where the intervener's intention is to prevent, restrict, or subdue movement of the body, or part of the body of another person'. Prone restraint was defined as 'the use of restraint in a face down or chest down position for any period of time'.

\section{The legal perspective}

The use of force to restrain a person may be legally and ethically justifiable in certain situations, for example to prevent a crime. Cases brought under the European Convention on Human Rights frequently engage one or more of the following provisions: the right 


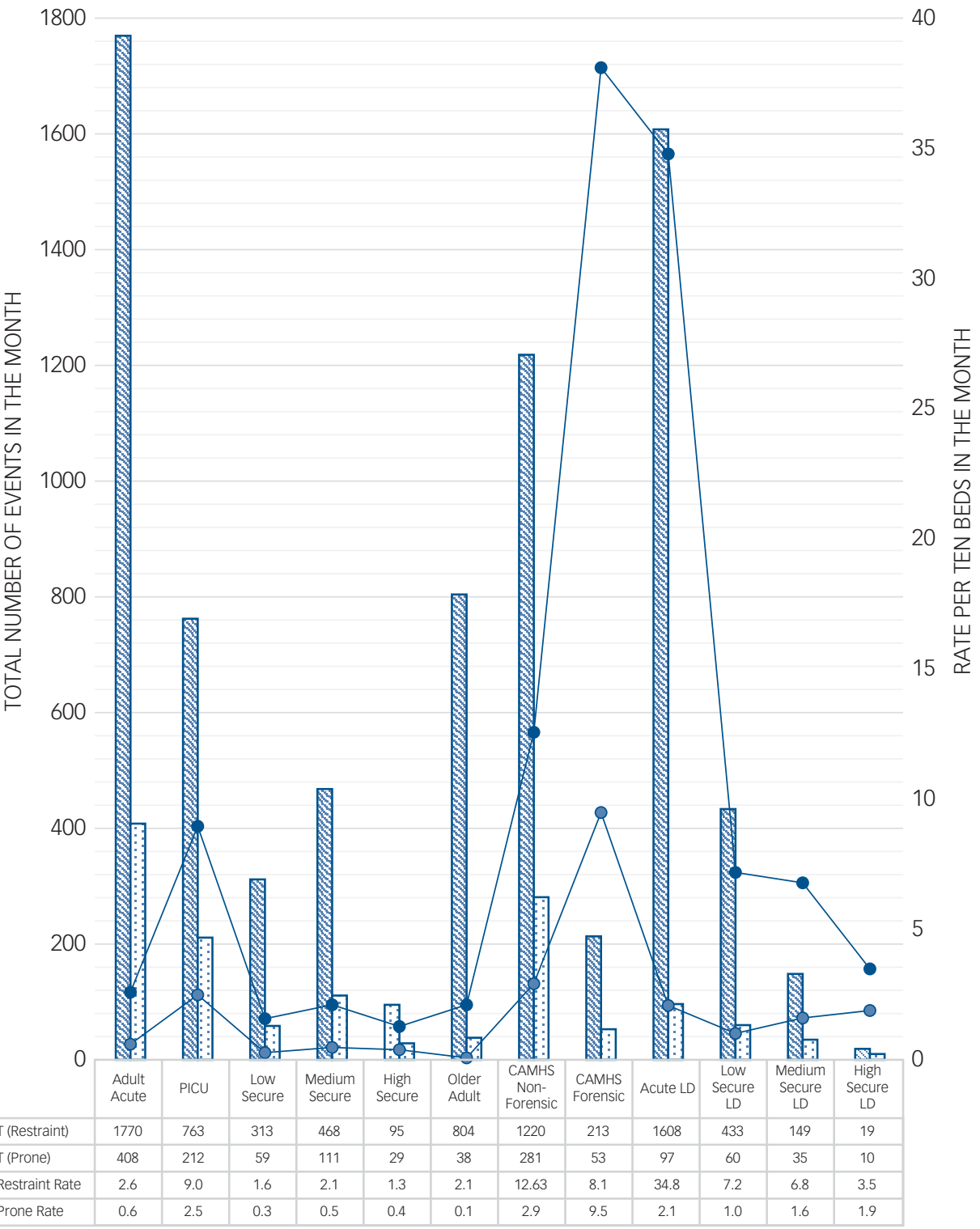

Fig. 1 Restraint incidents in psychiatric services in England in January 2016 (source data from National Health Service Benchmarking Network).

to life (art 2); the right not to suffer torture, inhuman or degrading treatment or punishment (art 3); the right to liberty and security (art 5) and the right to respect for private and family life (art 8). In healthcare, the ethical justification becomes more complex, mainly because of the wide range of circumstances in which force might be used; ranging for example from a confused patient wandering towards a busy road to preventing assaults on staff. Although the reasons for using force may differ, the requirement remains that any response must be necessary, reasonable and proportionate. $^{14,15}$ Practically, this means that the least possible restrictive intervention should be used with the minimum amount of force necessary to achieve the objective; any intervention beyond this is legally and ethically unjustifiable.

Where a person has been detained in hospital under the UK MHA, decisions regarding treatment may be taken without consent under part IV of the Act, and this includes the use of reasonable, least restrictive force. The use of force against a person who lacks capacity may be justified under the UK Mental Capacity Act 2005, provided it is necessary and proportionate to the likelihood and seriousness of harm occurring and is in the person's best interests.
Our understanding of the prevention and management of violence and aggression (PMVA) and the safer use of restraint has improved, but the notion of anything approaching an entirely safe method is still unrealistic. In 1998, it was noted that 'restraint is not itself harmless; some proportion of those who are restrained may die. We do not know what this proportion is, or how many others will come near death and be revived. As clinicians, we need to accept that restraint procedures are potentially lethal and to be judicious in their use. ${ }^{16}$ This is as true today as it was two decades ago.

Internationally, restraint fatalities are often associated with mechanical restraint but are typically the result of the use of physical force to immobilise. The more time it takes to complete the restraint procedure, the higher the risk of serious complications. ${ }^{1}$ Current initiatives have concentrated on measures to reduce aggression and thereby minimise the need for physical interventions. De-escalation training is now a standard part of most physical intervention training programmes, with the emphasis on bringing restraint to the earliest possible conclusion.

Combining best practice with legal and ethical principles produces a model in which restraint should be considered an emergency 
intervention that is avoided if possible; adapting prevailing conditions to deal with acute situations. Where restraint proves necessary, it must be properly recorded and investigated to see what lessons can be learned to prevent reoccurrence. Lessons learned can have a local and national impact. Following the restraint-related death of Jimmy Mubenga in 2010, the Home Office Manual for Escorting Safely was introduced as the sole approved training programme for Detention Custody Officers. ${ }^{17}$ Furthermore, a new system for use with minors $(\mathrm{MMPR})^{18}$ was introduced following concerns about the harm caused by restraint in juveniles.

Until recently, there has been considerable resistance to the standardisation of approaches to PMVA in healthcare settings. A unifying example has recently been developed by the UK's High Secure Services and endorsed by NICE. ${ }^{19}$ The 'Positive \& Safe Violence Reduction and Management Programme' has been produced to ensure that a standard skills programme is delivered by approved trainers. Although written specifically for high secure settings, much of the material is applicable to other settings because of its modular approach. It covers the prediction, prevention and management of aggression and violence, and is organised into a three level interventional framework.

\section{Safety of restraint positions}

Substantial controversy has arisen regarding the safety of restraint practices, particularly prone restraint, culminating in one set of official guidance proposing a ban of the use of this position. ${ }^{7}$ The published literature does not support such a simplistic view.

Although deaths have occurred during prone restraints, it is not clearly demonstrated that death is associated specifically with this position and the number of deaths directly associated to it is small. Hall et $a l^{20}$ studied 3.25 million police/public interactions which resulted in 2015 restraints in a prone position and 2358 in a non-prone position. One fatality occurred following restraint, which translates to a rate of $0.02 \%$, and this was in a non-prone position. There is no randomised controlled trial examining this issue and the challenges associated with such a trial are self-evident.

Laboratory research has been conducted into the physiological effects of restraint positions (see Table 1), examining variables such as lung function. A review by Barnett et al found that the studies reported reduced lung function in specific restraint positions, but this was commonly at a level considered clinically insignificant. ${ }^{30}$ The authors concluded that 'restraint position negatively affects ventilatory and other physiological functions, but to what extent in real world restraint situations is unknown.'

Many of the reviewed studies examined restraint positions associated with law enforcement, using handcuffs. These are of interest but have limited direct relevance to healthcare. Parkes \& Carson conducted laboratory lung-function testing of manual restraint techniques and found that some prone restraint positions caused significant reductions in lung function. ${ }^{25}$ Barnett et al conducted a similar study, demonstrating that small reductions in lung function in the prone position could be ameliorated by a modified arms placement. ${ }^{29}$

Although attention in the UK has focused on the prone position, fatalities have occurred in other positions. ${ }^{31}$ Laboratory testing of seated positions have demonstrated reductions in lung function that are substantially greater than those from prone restraint. ${ }^{28}$

Some authors have emphasised the role of other causal factors. Vilke et al highlighted the role of 'excited delirium', which may

\begin{tabular}{|c|c|c|c|c|}
\hline Source & $n$ & Subjects & Design/Interventions & Results \\
\hline Chan et al (1997) ${ }^{21}$ & 15 & $\begin{array}{l}\text { Male; } \\
\qquad \mathrm{BMI}<30\end{array}$ & $\begin{array}{l}\text { Exercised } 4 \text { min. Lung function tested. } \\
\text { Compared seated-control position } \\
\text { with hobble-prone position. }\end{array}$ & $\begin{array}{l}\text { Mean reduction in FVC: } 8 \% \text { in prone position, } 14 \% \text { in } \\
\text { hobble-prone position }(P<0.001) \text {. No significant } \\
\text { change in } \mathrm{O}_{2} \text { saturation. }\end{array}$ \\
\hline Chan et al (2004) & 10 & $\begin{array}{l}\text { Male (exclusion: unable } \\
\text { to be restrained) }\end{array}$ & $\begin{array}{l}\text { Compared seated-control with hobble- } \\
\text { prone or hobble-prone position + } \\
\text { maximum } 50 \mathrm{lb} \text { weight. }\end{array}$ & $\begin{array}{l}\text { Mean reduction in FVC: } 16 \% \text { in hobble-prone position } \\
\text { with } 50 \mathrm{lb} \text { weight. No significant change in } \mathrm{O}_{2} \\
\text { saturation. }\end{array}$ \\
\hline Meredith et al $(2005)^{23}$ & 8 & $\begin{array}{l}\text { Male/female + COPD; } \\
\quad \text { mean age }=66\end{array}$ & $\begin{array}{l}\text { Lung function tested. } \\
\text { Seated and prone positions, each with } \\
\text { hands in front or behind back. }\end{array}$ & $\begin{array}{l}\text { No significant change in lung function between } \\
\text { positions. Three participants could not tolerate prone } \\
\text { position and could not be tested. }\end{array}$ \\
\hline Micalewicz et al (2007) & 30 & $\begin{array}{l}\text { Male/female; } \\
\text { healthy }\end{array}$ & $\begin{array}{l}\text { MVV-seated compared with hobble- } \\
\text { prone position + max } 100 \mathrm{~kg} \text { weight. } \\
\text { Hobble-prone position }+60 \mathrm{~s} \\
\text { struggle. } \\
\text { Restraint/struggle } \mathrm{VO}_{2} \text { compared } \mathrm{v} \text {. } \\
\text { maximum running } \mathrm{VO}_{2} \text {. }\end{array}$ & $\begin{array}{l}\text { Mean } \mathrm{MVV} \text {, hobble-prone position with weight, showed } \\
70 \% \text { of seated } \mathrm{MVV} \mathrm{VO}_{2} \text { during restraint/struggle } \\
40 \% \text { of treadmill } \mathrm{VO}_{2} \text {. Concludes adequate ventilatory } \\
\text { reserve during hobble restraint. Prolonged struggle in } \\
\text { restraint difficult and participants 'waning' by } 60 \mathrm{~s} \text {. }\end{array}$ \\
\hline Parkes \& Carson $(2008)^{25}$ & 15 & $\begin{array}{l}\text { Male; } \\
\qquad \mathrm{BMI}<35\end{array}$ & $\begin{array}{l}\text { Lung function tested. } \\
\text { Standing control with four restraint } \\
\text { positions. }\end{array}$ & $\begin{array}{l}\text { Restraint lying flat, supine or prone, resulted in non- } \\
\text { significant reductions in lung function }(<10 \%) \text {. Prone } \\
\text { restraint with weight and/or flexing of body caused } \\
\text { reductions of up to } 27 \%(P<0.001) \text {. }\end{array}$ \\
\hline Vilke et al $(2011)^{26}$ & 10 & $\begin{array}{l}\text { Male/female; } \\
\qquad \mathrm{BMI}<30\end{array}$ & $\begin{array}{l}\text { Seated control } v \text {. exercise followed by } \\
\text { normal seated and exercise } \\
\text { followed by seated in restraint chair. } \\
\text { MVV and } \mathrm{O}_{2} \text { saturation measured. }\end{array}$ & $\begin{array}{l}\text { Non-significant reduction in } \mathrm{MW} \text { in restraint chair. No } \\
\text { change in } \mathrm{O}_{2} \text { saturation. }\end{array}$ \\
\hline Ho et al $(2011)^{27}$ & 23 & $\begin{array}{l}\text { Male/female; } \\
\qquad \mathrm{BMI}<30\end{array}$ & $\begin{array}{l}\text { USS measurement of diameter of IVC } \\
\text { before/after maximum } 147 \mathrm{lb} \\
\text { weight. Prone. }\end{array}$ & $\begin{array}{l}\text { Significant reductions in IVC. Increasing magnitude: } \\
\text { prone, prone + } 100 \mathrm{lb} \text {, prone }+147 \mathrm{lb}(P<0.0001)\end{array}$ \\
\hline Parkes et al $(2011)^{28}$ & 40 & $\begin{array}{l}\text { Male/female; } \\
\quad \mathrm{BMI}<35\end{array}$ & $\begin{array}{l}\text { Lung function tested. Standing control } \\
\text { v. seated leant forward and seated } \\
\text { leant forward + restraint. }\end{array}$ & $\begin{array}{l}\text { Leaning forward while seated showed significant } \\
\text { reductions in lung function. Mean reduction in FVC } \\
44 \% \text { (leaning forward, restrained, BMI }>25 \text { ) }\end{array}$ \\
\hline Barnett et al $(2013)^{29}$ & 25 & $\begin{array}{l}\text { Male/female; } \\
\quad \mathrm{BMI}<30\end{array}$ & $\begin{array}{l}\text { Lung function tested. Seated control } v \text {. } \\
\text { three prone positions. }\end{array}$ & $\begin{array}{l}\text { All prone positions resulted in significant reductions in } \\
\text { lung function }(P<0.001) \text {. A prone position with the } \\
\text { arms allowing support under the participants caused } \\
\text { least reduction ( } 11 \% \text { reduction). }\end{array}$ \\
\hline
\end{tabular}


contribute to death due to acute behavioural disturbance, cardiovascular effects of autonomic arousal and hyperthermia. ${ }^{32}$ Karch discussed the role of sudden cardiac death, the causation of which is not fully understood in the context of death following restraint. ${ }^{33}$

We know that death can occur during or following restraint; the infrequency and complex circumstances of these events hamper scientific investigation in the real world. Laboratory simulations point to some, but not all, positions inhibiting lung function. Ethical constraints prevent the full recreation of fatal events in laboratory studies using human participants, yet front-line clinicians require guidance. Such guidance needs to be balanced, practical and reflect the complexity and uncertainty of the current state of knowledge.

Reducing the risks also requires that organisations acknowledge and actively manage the processes that may be associated with its misuse, which may be indicative of the development of pathological cultures. Approaches to reduce the use of restrictive interventions now exist, targeting the prevention of such cultural influences on practice and promoting the development of safer therapeutic cultures; an example of such an approach is the Safewards Model (http://www.safewards.net/).

\section{Medical, psychiatric and psychological perspectives}

The medical complications associated with physical restraint encompass two groups: exacerbations of underlying physical disease and those arising de novo due to the act of physical restraint. Psychiatric patients are more likely to experience comorbid physical health disorders. Pre-existing respiratory, cardiovascular or neurological system disorders can increase the risk of complications associated with restraint. Examples include chronic obstructive pulmonary disease, cardiomyopathy and epilepsy. Restraint itself has been associated with complications across all systems, including muscle, bone, biochemistry, breathing/respiration and circulation. Examples of complications include muscle trauma, fractures/dislocations, metabolic acidosis, thromboembolism and arrhythmia.

In physical restraint, a confluence of factors can lead to medical emergencies. Consider the scenario where physical restraint position may restrict ribcage movement and uplift the abdominal organs. Clinicians leaning into the patient's back may limit lung expansion, the patient's agitation will increase oxygen demand, and medical risk factors such as obesity, sedative medications and respiratory disorders may reduce respiratory effectiveness. It is conceivable that such a clinical scenario may lead to restraint asphyxia, a form of positional asphyxia in which body position results in insufficient oxygen intake. The risk of fatal asphyxia may be reduced by monitoring during restraint, and pulse oximetry has been used to supplement visual observation. ${ }^{34}$ That said, pulse oximetry primarily detects hypoxia and may not detect hypercapnia, the latter has been associated with restraint asphyxia and acidosis. $^{35,36}$

In comparison with physical complications, mental disorders receive little coverage as a complication in physical restraint. Psychotropic medications cause several side-effects (e.g. extrapyramidal side-effects, pro-arrhythmic states, sedation) that can seriously compromise safety.

The negative psychological complications of physical restraint and the compound effect of enforced medication can lead to powerful experiences which evoke shame, humiliation, rage and fear. Patients in the acute mental health system commonly have significant trauma histories and physical restraint even by well-meaning clinicians may be re-traumatising, replicating the unconscious dynamics of past abuse. Such scenarios can lead to a violent and vicious circle. Proposed strategies to mitigate the potential negative psychological effects of restrictive interventions on patients and staff include the practice of debriefing. ${ }^{8}$ Although the concept of debriefing has an intuitive appeal, its effectiveness has yet to be fully established and requires further research.

\section{Summary and conclusions}

Physical restraint is part of a hierarchy of responses employed in the management of acute disturbance. The central therapeutic objective with most restrictive interventions is that of regaining a sense of control. Legal and ethical justifications for restraint - binding the concepts of necessity, reasonableness and proportionality support clinical decision making, which often requires complex risk-benefit analyses in the context of urgent and immediate response.

One cannot overstate the counter-therapeutic impact of physical restraint on patients and clinicians. Restraint done poorly can lead to malignant shifts in the sense of hope, opportunity and control. It should be used when absolutely necessary in an emergency, for the shortest time possible, and by clinicians who are trained in an approved restraint method.

Much of the debate around restraint guidance is dominated by clinicians, academics, regulators and policy makers. Other areas of mental health have been more successful in developing a co-productive relationship with the patient, and this may be required to change the prevalent culture around restraint and restrictive interventions in general.

There is variation in the use of restraint across the UK. Confounding stems from heterogeneity of service profiles, organisational reporting bias and definitional confusion. The most recent data capture by the NHSBN evidences considerable variation, but also provides the opportunity to look for root causes.

Much has been made in the UK of a perceived association between prone restraint and increased risk of negative outcomes. Restraint (prone or otherwise) rarely occurs in isolation; it is almost always part of a potentially lethal set of dynamic factors which in confluence can lead to serious negative outcomes for both patients and clinicians. In our opinion, the focus on positions may be an unhelpful and confusing distraction. As it stands today, the limited evidence base does not support effectively 'banning' of any position. Any restraint intervention delivered poorly has the potential to lead to serious negative outcomes. More research is required before we can reliably state the level of risk attached to a particular position in a particular clinical circumstance.

The real challenge for service providers is to ensure that while a focus on reducing restriction is required - when restrictive interventions (including restraint) are unavoidable, the full range of interventions should be available in clinical settings to provide a safe and effective crisis response. A clinical setting with a multidisciplinary team trained in de-escalation (with expertise and skills in the use of rapid tranquilisation and therapeutic restraint), access to an extra-care area, access to a seclusion room, and the ability to access differing levels of security will operate with a distinctly different philosophy of care to one that has limited options.

Faisil Sethi, FRCPsych, Maudsley Hospital, South London and Maudsley National Health Service Foundation Trust, London; John Parkes, PhD, MMedSci, Coventry University; Eric Baskind, LLB, LLM, MCIArb, Liverpool John Moores University; Brodie Paterson PhD, MEd, Crisis and Aggression Limitation and Management (CALM) Training Limited, $\mathrm{PhD}, \mathrm{MEd}$, Crisis and Aggression Limitation and Management (CALM) Traini
Menstrie; Aileen O'Brien, MRCPsych, St. George's University of London.

Correspondence: Faisil Sethi, Maudsley Hospital, London SE5 8AZ. Email: faisil.sethi@ slam.nhs.uk

First received 7 Mar 2017, final revision 9 Aug 2017, accepted 25 Sep 2017 


\section{References}

1 Høyer G. The Use of Restraints in Psychiatric Institutions. European Committee for the Prevention of Torture and Inhuman or Degrading Treatment or Punishment, 2012 (http://www.cpt.coe.int/en/working-documents/CPT-2012 28-eng.pdf)

2 Bernhardsgrutter R, Conca A, Hatling T, Janssen W, Keski-Valkama A, Lepping P, Mayoral $F$, et al. Incidence of seclusion and restraint in psychiatric hospitals: literature review and survey of international trends. Soc Psychiatry Psychiatr Epidemiol 2010; 45: 889-97.

3 Whittington RE, Baskind E, Paterson B. Coercive measures in the management of imminent violence: restraint, seclusion and enhanced observation. In Violence in Mental Health Settings: Causes, Consequences, Management (eds Richter D, Whittington R): 145-72. Springer Verlag, 2006.

4 Royal Australian and New Zealand College of Psychiatrists. PS61 PPP Minimising the Use of Seclusion and Restraint in People with Mental IIIness. Royal Australian and New Zealand College of Psychiatrists, 2016 (https://www. ranzcp.org/Files/Resources/College_Statements/Position_Statements/PS-61Minimising-the-use-of-seclusion-and-restrain.aspx).

5 Mind. Mental Health Crisis Care: Physical Restraint in Crisis. Mind, 2013 (https:// www.mind.org.uk/media/197120/physical_restraint_final_web_version.pdf).

6 Department of Health. Winterbourne View Hospital: Department of Health Review and Response. Department of Health, 2012 (https://www.gov.uk/government/publications/winterbourne-view-hospital-department-of-healthreview-and-response)

7 Department of Health. Positive and Proactive Care: Reducing the Need for Restrictive Interventions. Department of Health, 2014 (https://www.gov.uk/ government/uploads/system/uploads/attachment data/file/300291/ JRA_DoH_Guidance_on_RH_Summary_web_accessible.pdf).

8 National Institute for Health and Care Excellence (NICE). Violence and Aggression: Short-term Management in Mental Health, Health and Community Settings. Nice, 2015 (http://www.nice.org.uk/guidance/NG10)

9 Department of Health. Code of Practice: Mental Health Act 1983. The Stationery Office, 2015.

10 Care Quality Commission. Brief Guide for Inspection Teams: Restraint (Physical and Mechanical). Care Quality Commission, 2015 (https://www.cqc.org.uk/sites/ default/files/20160422_briefguide-Restraint_physical_mechanical.pdf.pdf)

11 National Health Service England. The Importance of Vital Signs During and After Restrictive Interventions/Manual Restraint. NHS/PSA/W/2015/011. Nationa Health Service England, 2015 (https://www.england.nhs.uk/wp-content/ uploads/2015/12/psa-vital-signs-restrictive-interventions-031115.pdf)

12 National Health Service Wales. The Importance of Vital Signs During and After Restrictive Interventions/Manual Restraint. PSN 023. National Health Service Wales, 2016 (http://www.patientsafety.wales.nhs.uk/sitesplus/documents/ 1104/PSN023\%20The\%20importance\%20of\%20vital\%20signs\%20during\% 20and\%20after\%20restrictive\%20interventions.pdf)

13 https://www.nhsbenchmarking.nhs.uk/news/use-of-restraint-feedbackevents-for-mental-health-camhs-and-ld

14 UK Criminal Justice and Immigration Act 2008, s.76.

15 UK Mental Capacity Act 2005, ss 5, 6.

16 Milliken D. Death by restraint. Can Med Assoc J 1998; 158: 1611-12.
17 Home Office \& Immigration Enforcement. Use of Restraint(s) for Escorted Moves. Detention Services Order 07/2016. Home Office \& Immigration Enforcement, 2016 (https://www.gov.uk/government/publications/use-ofrestraints-for-escorted-moves)

18 Ministry of Justice. Minimising and Managing Physical Restraint. Ministry of Justice, 2012 (https://www.gov.uk/government/publications/minimising-andmanaging-physical-restraint).

19 National Health Service. Positive and Safe: Violence Reduction and Management Programme. http://www.wlmht.nhs.uk/pmva-manual

20 Hall C, Votova K, Heyd C, Walker M, MacDonald S, Eramian D et al. Restraint in police use of force events: examining sudden in custody death for prone and not-prone positions. J Forensic Leg Med 2015; 31: 29-35.

21 Chan TC, Vilke GM, Neuman T, Clausen JL. Restraint position and positional asphyxia. Ann Emerg Med 1997; 30: 578-86.

22 Chan TC, Neuman T, Clausen J, Eisele J, Vilke GM. Weight force during prone restraint and respiratory function. Am J Forensic Med Pathol 2004; 25: $185-9$

23 Meredith C, Taslaq S.Min Kon O, Henry J. The cardiopulmonary effects of physical restraint in subjects with chronic obstructive pulmonary disease. J Clin Forensic Med 2005; 12: 133-6.

24 Michalewicz BA, Chan TC, Vilke GM, Levy SS, Neuman TS, Kolkhorst FW. Ventilatory and metabolic demands during aggressive physical restraint in healthy adults. J Forensic Sci 2007; 52: 171-5.

25 Parkes J, Carson R. Sudden death during restraint: do some positions affect lung function. Med Sci Law 2008; 48: 137-41.

26 Vilke GM, Sloane C, Castillo EM, Kolkhorst FW, Neuman TS, Chan TC. Evaluation of the ventilatory effects of a restraint chair on human subjects. J Emerg Med 2011; 40: 714-8.

27 Ho JD, Dawes DM, Moore JC, Caroon LV, Miner JR. Effect of position and weight force on inferior vena cava diameter - implications for arrest-related death. Forensic Sci Int 2011; 212: 256-9.

28 Parkes J, Thake D, Price M. Effect of seated restraint and body size on lung function. Med Sci Law 2011; 51: 177-81.

29 Barnett R, Hanson P, Stirling C, Pandyan AD. The physiological impact of upper limb position in prone restraint. Med Sci Law 2013; 53: 161-5.

30 Barnett R, Stirling C, Pandyan D. A review of the scientific literature related to the adverse impact of physical restraint: gaining a clearer understanding of the physiological factors involved in cases of restraint-related death. Med Sci Law 2012; 52: 137-142.

31 Park KS, Corn CS, Henderson So. Agitated delirium and sudden death: two case reports. Prehosp Emerg Care 2001; 5: 214-6.

32 Vilke GM, Payne-James J, Karch SB. Excited delirium syndrome: redefining an old diagnosis. J Forensic Leg Med 2012; 19: 7-11.

33 Karch SB. The problem of police-related cardiac arrest. J Forensic Leg Med 2016; 41: 36-41.

34 Sheldon $\mathrm{M}$. The use of pulse oximetry in response to violence. Mental Health Practice 2006; 9: 32-5.

35 Hick JL, Smith SW, Lynch MT. Metabolic acidosis in restraint associated cardiac arrest: a case series. Acad Emerg Med 1999; 6: 239-43.

36 Alshayeb $\mathrm{H}$. Lactic acidosis in restrained cocaine intoxicated patients. Tenn Med 2010; 103: 37-9. 